Review

\title{
Australian Renewable-Energy Microgrids: a Humble Past, a Turbulent Present, a Propitious Future
}

\author{
Simon Wright ${ }^{1}$, Mark Frost ${ }^{2}$, Alfred Wong ${ }^{3}$ and Kevin A Parton ${ }^{4, *}$
}

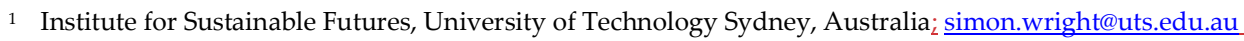

2 School of Business, Charles Sturt University, Bathurst, Australia; mfrost@csu.edu.au

3 School of Business, Charles Sturt University, Bathurst, Australia; awong@csu.edu.au

4 School of Business, Charles Sturt University, Orange, Australia; kparton@csu.edu.au

* Correspondence: kparton@csu.edu.au

\begin{abstract}
As the global energy market undergoes a wholesale transformation accelerated by the need to decarbonise, a rapid transition to renewable energy and the mass deployment of distributed energy resources, autonomous energy networks or microgrids are emerging as an attractive mechanism for the delivery of electricity to end users. Yet in Australia, at least, relatively little is known about key aspects of microgrids that are fundamental to their successful deployment, not least the more commercial and economic elements rather than the purely technical. Drawing on the extant global literature on microgrids, this paper explores the most important of these aspects including business models, ownership and investment. Identifying the ambiguity, inconsistency and uncertainty evident in many of the feasibility studies currently in train across Australia, this paper highlights specific areas for future research that need to be addressed if the full potential of microgrids is to be realised in the context of a global energy transition both domestically and internationally.
\end{abstract}

Keywords: microgrids; Australia; ownership; business models; value streams; community; energy efficiency.

\section{Introduction}

The energy sector in Australia is undergoing a radical transformation, driven by an array of factors, most notably a rapid decrease in the cost of renewable energy relative to fossil fuels; a changing climate and urgent need to decarbonise; deregulation and disruption in all parts of the value chain; and accelerating technological advances that are flattening markets and empowering customers. Emerging models of generation and distribution are challenging the status quo yet are stymied by a market in transition and a network struggling to keep pace with a rapidly changing marketplace.

At the same time, Australian government policy towards energy has been a confused array of interventions and market-based instruments, including a carbon tax and its abolition, direct action policy in terms of subsidies for investment in renewable energy generation, and renewable energy targets. Much of this policy has been ideologically driven, though with an environmental spin to make it publicly digestible [1].

While these events have been occurring, generating capacity is transitioning away from traditional generators towards larger numbers of renewable energy developers. Thus, 
electricity generation is now in the hands of many and more diversified firms, with various forms of ownership. It is amid this whirlpool of opportunity and increasing bottleneck and expanse of network connectivity that the microgrid (MG) expansion has emerged as an alternative to distribution, particularly for regional and remote communities.

In this context, our research investigates the current state of play in MG development in Australia and highlights significant constraints facing this development. By reviewing the extant literature on MGs, the objectives of the research reported in this paper are to assess the current state and likely future of Australian MGs and to identify the obstacles common to the many projects under development. In the first stage of this review, the definition of a MG is clarified. Then, in the next section, recent developments in the Australian electricity network and the role of MGs are described. This is followed by consideration of three of the most challenging elements of MG development - business models, ownership structures, and the financial sustainability of MGs. We then examine the special role of community MGs in Australia. This is followed by a summation of major conclusions.

\section{Materials and Methods: What is a Microgrid?}

From humble beginnings, microgrids are experiencing a surge in interest both across Australia and internationally. Important initial questions emerge as to the number of MGs in Australia, their share of the electricity market, and their defining characteristics? These questions are unable to be answered without consideration of the precise definition of what constitutes a MG. Unsurprisingly, different researchers have defined MGs in different ways. Consequently, [2] identify this ambiguity and suggest the need for a clear definition. ([3] p.1) puts forward the simple definition: "a microgrid is an autonomous or local energy grid, with the control capability to operate separately to the traditional grid". While a step forward, this is insufficient as the basis for useful analysis. Indeed, the author confirms as much by stating that "the term microgrid can have many different meanings in regard to size, purpose, load capability, sustainability and infrastructure in relation to the grid". [4] utilise the USA Department of Energy definition of MGs as a group of interconnected loads within clearly defined boundaries with a single controlling entity that can operate in island-mode or connected to the wider grid. There is also diversity in the size of MGs, and source of power connected, including solar (a few houses with panels, a factory or a small-scale solar farm with community interest) compared with a hybrid diesel and renewable MG. MGs can be found on remote mine sites delivering electricity to a single entity as well as in a regional town or urban precinct supplying power to multiple businesses and households. [1] includes all sizes of MGs in his definition ranging from the North-West Interconnected System in the Pilbara Region of Western Australia to isolated cattle stations. With this definition, he estimates that in Australia there are "more than one thousand small, islanded systems and microgrids" (p. 183). The problem with this all-encompassing definition is that it again does not lend itself to useful analysis. A more practical approach to defining a MG is supplied by ([2] p.15): "A system for managing the electricity supply and demand of customers, in a way that efficiently integrates local sources of generation and storage of electricity ('local supply') with electricity supplied from or exported to the grid ('network supply')". This is 
"a fully functioned local electricity network and trading market with dynamic optimisation of resources interacting with an external energy market". This definition describes the type of MG considered in the remainder of this article. It is much more than a remote mine site or cattle station. It would typically include a site with its own network; its own electricity generation and storage; a single connection point to the grid, but with the possibility of operating independently of the grid should the need arise; and a dynamic control system related to demand and supply. In addition, if it fulfils certain conditions, a MG could become a Small Generation Aggregator (SGA) and thereby achieve certain market advantages (see discussion in Section 3).

\section{Results}

\subsection{Recent Developments in the Australian Electricity Network and the Changing Role of Microgrids}

Despite claims that conditions in Australia are ideal for a massive expansion in MGs [5], and that Australia's long experience with MG is a strong basis for it to become a leading nation in the export of MG-related technology [6], the aggregate amount of electrical energy generated by the nation's MGs remains small [7]. Indeed, compared with some parts of Europe and North America, Australian microgrids are at an embryonic stage [8]. This suggests that to understand both the current status and likely future, it is worth examining closely recent trends in the development of MGs, paying particular attention to facilitating conditions and barriers.

Figure 1 shows the relationships between the external environment, the MG business model, MG ownership structure, its financial sustainability and MG growth. The business model and ownership structure are dependent on various components of the external environment, including state of the technological development, the legal and institutional framework, and government policy. A MG's business model and ownership structure tend to evolve simultaneously, with each affecting the development of the other. Together the business model and ownership structure are the key aspects of the non-technical internal environment of the MG. Next, as shown in Figure 1, the financial sustainability of the MG is dependent on the ability of the business model and ownership structure to respond to the external environment. Finally, financial sustainability of the MG is a prerequisite for its growth. In this section we consider the external environment.

According to ([5] p. i), "Microgrids are the building blocks of our energy future. Smallscale electricity networks that can operate independently of the surrounding grid, they are a tailored solution optimised for cost, reliability and sustainability. By intelligently networking and managing distributed energy resources and loads, they can achieve efficiency dividends and capture new revenue streams." To understand the positioning of MGs, it is necessary to consider the changes that are taking place at a macro level in electricity supply and consumption in Australia. Significant among the facilitating conditions are the expansion of distributed generation; the declining costs of solar and wind generation and battery storage; the use of digital metering, sensing, communication 
and control; electric vehicles and the potential for virtual power plants; and improved

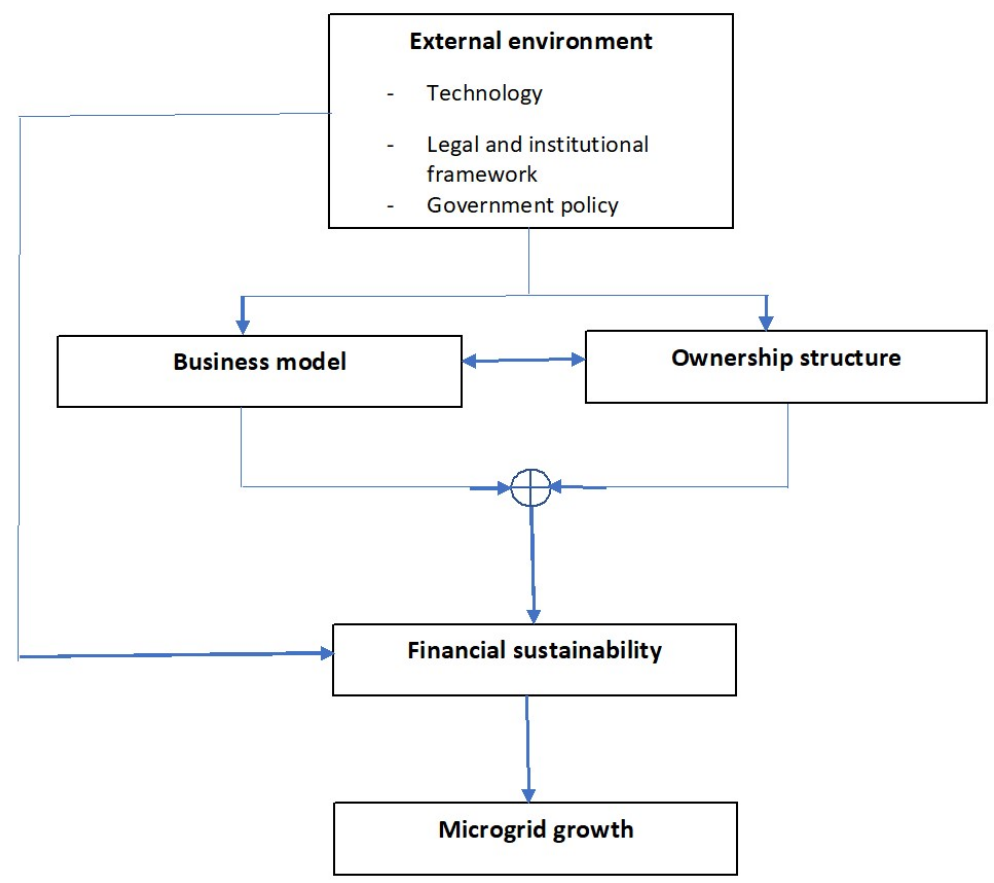

Figure 1: Internal and external relationships of Australian microgrids

analytical methods for optimal control of both individual MGs and the overall network. In addition to these conditions, MGs may themselves offer several advantages including higher system efficiency associated with co-location of energy sources and uses, enhanced reliability of the overall network and employment generation particularly in regional locations.

Renewable energy in the form of wind turbines and solar PV is the technological revolution that has enabled distributed generation and challenged the Australian electricity network (or "the grid") over the last 15 years. Built since the 1880s, the poles and wires that comprise the national electricity grid have enabled centrally generated electricity to be distributed to consumers across Australia. It is a relatively simple system, with electricity traditionally generated in coal-fired power stations, a step-up transformer to permit efficient distribution across the high-power grid system, a step-down transformer close to consumers, and a connection to each home or business. This network is located around the coast from northern Queensland to South Australia, with interconnectors between the eastern states, and a separate grid around Perth in Western Australia. Prior to the 21st Century almost all electrical power was generated centrally in coal-fired power stations, and distributed outwards to consumers using the poles and wires of the grid. However, the continuing rapid expansion of renewable energy production is accelerating the transition to distributed generation year-by-year.

The key components of the network now include not only the major generators (largely using coal-fired power stations); but also new large-scale renewable generators (mostly 
wind and solar-powered, but also pumped hydro) owned independently; large battery systems; businesses with their own generating capability (usually solar); households with PV solar panels on their roofs; MGs; and the use of various battery systems by each of the above entities. This now amounts to a much more complex and decentralised grid than existed previously.

Home solar PV systems and large-scale wind and solar farms represent additional components that pose a challenge to the grid. Over the last decade more than two million rooftop solar systems have been installed in Australia. Almost 30\% of homeowners now have the ability to generate part of their own electricity and be paid to export the surplus energy to the grid; a response to the rapidly declining real price of solar panels and the steadily increasing price of network connectivity. This revolution is likely to continue further as small-scale battery technology becomes cheaper in line with a flattening technological cost curve. However, an important cost to be considered when investing in household solar and storage is the aggregate over-investment in excess capacity of the generation and battery systems. This is where MGs offer substantial opportunities from sharing the costs of equipment and especially batteries.

Another impact of the recent investment in renewables is the costs it imposes on the grid. There are two major types: the costs associated with the risks of power cuts; and the costs of maintaining the quality of the electricity supply in terms of voltage and frequency. The first occurs because (1) the declining costs of electricity generation using wind and solar are driving the closure of coal-fired power stations as they reach the end of their design life and become uncompetitive relative to wind and solar; and (2) the amount of electricity produced by wind and solar generation is highly variable. With respect to this variability, clear sunny days with strong winds produce maximum output, still nights minimum. This requires the rest of the electricity generators, largely coal and gas-fired power stations, to vary their output in a countervailing manner to match the electricity demand. Hence, there is both less generating capacity on average needed from these fossil fuel sources, and at the same time, a greater stabilising role is being demanded from their smaller capacity. The second type of cost, related to maintaining the quality of electricity supply, occurs whenever a new source of electricity enters the grid and consequently increases network voltage. For a single home with new solar panels, the voltage change would be imperceptible and no quality problem would be presented. However, as many more homeowners connect solar panels to the grid, the sheer quantity of new electricity supplied may result in local voltage changes that trip household inverters linked to those panels and prevent supply of electricity and ensuing income. A longer-term solution would be to replace the grid transformers so that the local network can accommodate more variable supplies. This could be regarded as an external cost of the switch to renewables which is imposed on the network service providers. An alternative response is to restrict supply to the grid, something that routinely happens at an industrial scale at capacity-constrained locations especially in the regions.

In relation to both types of cost - risks of power cuts and quality of electricity supply MGs could offer possible solutions [9]. If the number of MGs with storage capacity for 
electricity increases substantially, they are likely to provide a stabilising influence on the grid by shaving or reducing electricity demand during peak periods. In addition, some existing MGs, such as on King Island, have been used to discover how best to integrate intermittent renewable energy where the MG has been able to operate without system failure at an average level of 65\% renewables ([1] p.199). There are clearly lessons here for the operators of the wider grid.

While commenting on the renewable energy experience in Europe, [10] highlight a possible complexity around the expansion of MGs in Australia. An increase in the generation capacity from MGs can either add to existing supply or meet a generation shortfall, with each impacting the marginal cost (and price) of this new electricity. This can impact both total and intra-day supply and demand, such that the impact on price varies. For example, if an existing supplier creates a MG, they may partially absorb the output changes and price implications when compared with a new supplier.

In summary, a MG is a grouping of electricity-producing and storing resources, and consuming loads in a particular location. It could be connected to the grid or it could stand alone. It could connect just a few houses in a remote location, or several commercial businesses in a precinct, or a whole community or town. A MG consists of various components - local electricity generation, local consumption, energy storage, a mini-grid management system linked to the network using a smart system to distribute load and storage efficiently, and an internal electricity network.

In Australia, most MGs are connected to the grid which raises questions about the price that electricity is sold to and purchased from the grid. Unless being a Small Generation Aggregator (SGA) in its own right, the MG must sell to a licensed retailer or an SGA. Retailers must pay either a flat or time-varying minimum feed-in tariff which is typically determined by a state-based regulator such as the Energy Services Commission in the State of Victoria. Retailers have the flexibility to offer higher than minimum feed-in tariffs, while SGAs can sell either to retailers or directly into the wholesale market.

MGs usually purchase any additional demand that they themselves are unable to supply from a retailer. However, MG owners can also register as a market customer with the Australian Energy Market Operator (AEMO), and classify at least one connection point as a "market load", enabling them to purchase directly from the spot market. If this market participation is solely to meet their own needs, they can register without a licence. Optimal use of their own resources may be achieved by purchasing electricity (say, to recharge batteries) from the spot market at times of the day when the price is particularly low.

The following section explores some of the key challenges emerging for MGs.

\subsection{Emerging Challenges and Opportunities}

The developments described above create an unprecedented setting as MGs move from a niche to mainstream participant in the Australian energy market. MGs can provide several benefits including reducing emissions through renewable energy generation and lower transmission costs, as well as improving energy security and access as climate disruption increases. This sees different challenges and opportunities emerge that are discussed 
below. [11] observed that while the technological foundations for establishing and operating MGs are sound, the lack of economics and business considerations is stalling their progress. According to ([12] p. 2) the MG business model is defined by "the plan of the organization for successful operation of the business, determining revenue stream, target customer, product and financial model." Viable business models and benefit sharing need to receive much more attention if MGs are to be deployed commercially at scale [13]. In addition, it is clear that ownership structures and business models are inextricably linked. For example, community MGs are far more likely to give a high priority to social and environmental goals.

\subsubsection{Ownership structures and business models}

As MGs move into being a mainstream participant in energy generation, a commensurate development needs to occur that improves the linkages between MGs, their consumers, electricity generators and suppliers. MGs provide potential benefits in energy security, generation and transmission, which if coordinated well, can benefit all participants in the energy market. For these reasons it is important that some form of policy framework and/or process is developed to facilitate this interaction among participants. From these interactions, business models, ownership structures, and pricing can be developed.

[14] identify three main business models for MGs that essentially define the boundaries of possibilities. They are based on either consumer ownership, utility-company ownership or community ownership. The first is "plug and play" where the consumer can become partly independent of conventional power suppliers. Any microgeneration unit is owned by the householder and is operated by them to capture value streams. These can take various forms from maximising revenues from exporting to the grid to consuming as much electricity on site as possible if the price for exports is low. The second is the companydriven business model where investing energy companies retain ownership and charge for the electricity. Here the consumer takes a passive role and the value streams are accrued by the company. These value streams typically take the form of using the MG to balance supply and demand in the grid and avoiding the need to purchase wholesale electricity at particular times. The third model is a community microgrid, whereby consumers with or without the assistance of an electricity company pool their resources. This is intermediate between the other two, and requires a high level of consumer engagement because, while they will have some control over their own generating unit (and battery, if they own one), they also need to be involved in the process of guaranteeing the demand-supply balance within the MG.

[12] extend the types of business models to six. The most relevant of these for the Australian MG context are (1) consumer owned, including majority consumer owned in a public-private partnership, (2) utility ownership for remote sites where it is more efficient to generate locally rather than using grid power, (3) service company owning the generating assets of the MG and supplying the consumers at a price that is lower than grid electricity, and (4) an energy service company (ESCO) that provides a comprehensive service agreement to design and run the microgrid to enhance its efficiency. Types (1), (3) 
and (4) can all evolve into a similar consumer-based type that is well-positioned to generate the necessary finance under Australian conditions (see details in Section 3.2.3). Looking specifically at the community-owned model, [12] offer a simple framework for MG development incorporating community, technology, institutional structure, financing and revenue generation (see Figure 2). This model provides a useful analytical framework for MGs in any type of context or ownership, as can be observed by examining the box labelled "Community" with the five aspects: motivation and goals, energy demand, value proposition, income level, and level of reliability to achieve. For example, the difference between a MG for an urban business precinct and a remote rural MG is in the subcomponents that compose these five aspects and their weightings. Each type of MG can also differ in a similar way to this across each of the aspects described within the other boxes of Figure 2.

Developing the revenue-generating aspect of Figure 2, [13] highlights some of the complexities identified in the literature surrounding the definition of business models for MGs. The review confirms that business models are intrinsically linked to many contextual factors including the role of key stakeholders such as power utilities, distribution system operators (DSOs) and customers, the nature of asset ownership, the level of service aggregation and the management of the overall operation. It is evident that innovative business models are evolving across the entire value chain necessitating a raft of new issues to be solved relating to customers, metering and data to name but a few. Finally, while confirming that the business cases for MGs continue to evolve and that the different segments (commercial, utility, remote, etc.) are leaning towards different business models, [15] notes that MGs will ultimately lower the cost per kilowatt hour of electricity. It is these potential benefits that are explored in the following section.

\subsubsection{Value streams}

There are a number of benefits of MGs and while such value propositions are just one subcomponent of the analytical framework of Figure 2, they are of prime importance. First, looking at local energy markets for MGs specifically, research suggests that MGs can reduce power costs [16]. Second, local energy markets can also curb the market power of utilities, especially if they are implemented by privately owned MGs. Third, local energy markets can facilitate the integration of intermittent distributed renewable generation into the existing energy infrastructure and contribute to overall grid stability as they provide MGs with a platform to coordinate load requirements locally. Next, local energy markets increase energy efficiency since energy is consumed close to generation and less energy is lost during transmission. Finally, pricing aspects of MG operation can provide value to the MG owners [17]. Given the early stages of MG-related research in Australia, the value of these benefits for MGs is yet to be accurately quantified. Additional theoretical and experimental investigations for real-world applications are required to gain a better understanding of how local energy markets perform in different economic contexts (e.g., feed-in-tariffs vs. net metering).

First, in the area of costs, a 2018 study on cost models for MGs in the US dominated by combined heat and power cogeneration (CHP), natural gas and diesel, the national 
Renewable Energy Laboratory (NREL) identified community models as providing the cheapest electrical power and commercial models the most expensive [18]. Installations of between $2 \mathrm{MW}$ and 10MW of generation capacity had economies of scale, while conventional generation was more expensive than renewable generation. Soft costs proved highly variable between projects. Finally, community projects, despite providing the cheapest power, had the highest infrastructure costs because they tended to require

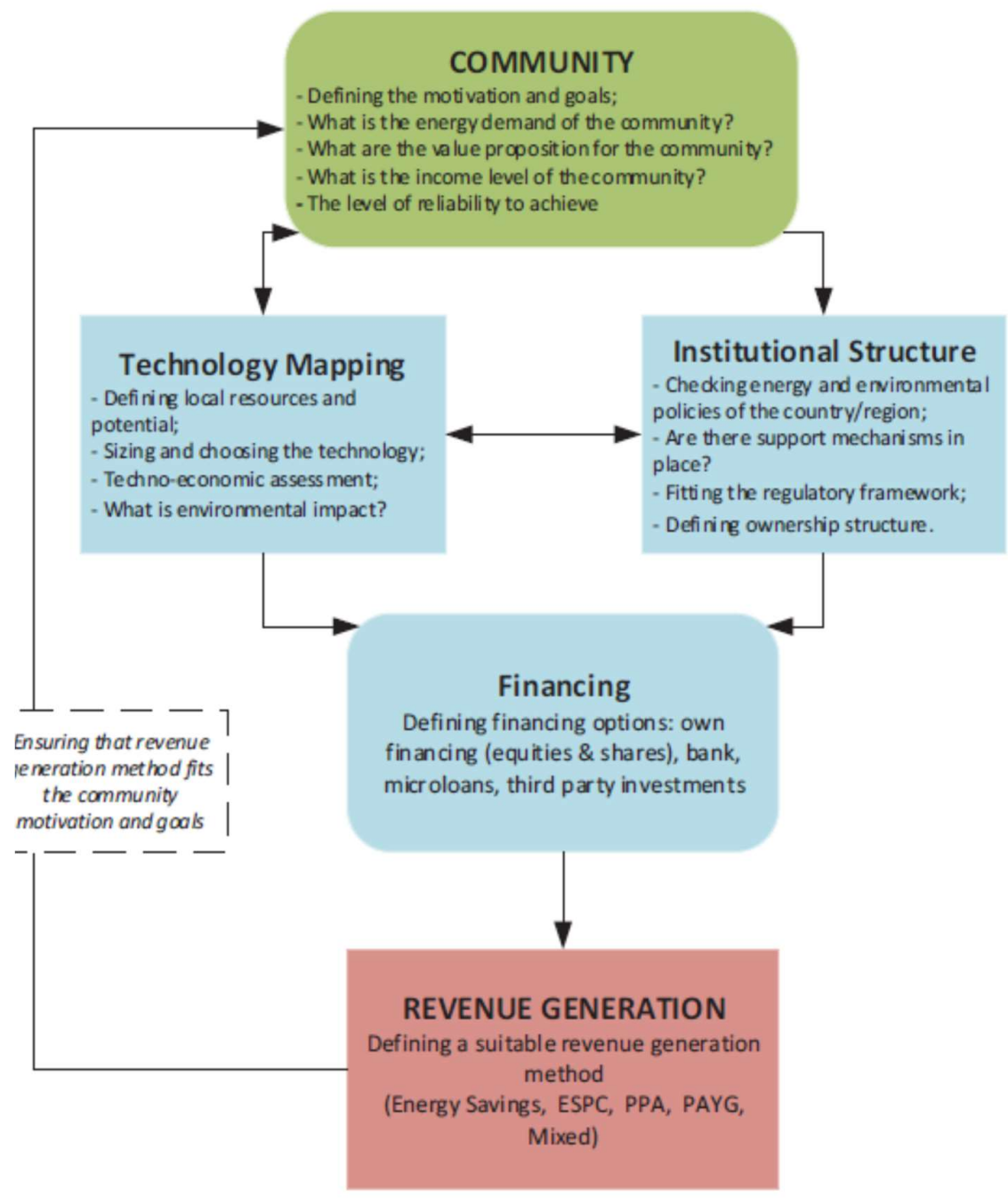

Figure 2: Framework for community microgrid business models Source: [12]

medium voltage islanding and hence expensive supporting equipment such as switchgear and data acquisition systems.

In a similar study on community MGs which highlighted the need for their greater commercial deployment and an improved understanding of business models, [19] note 
that where reliability is not a major issue, a DER alone represents a net cost to the customer. Second, under a net metering scheme, as grid electricity prices increase, DERs become increasingly attractive to install and operate; customers are incentivized to self-generate and consume instead of purchasing power from the grid. Third, designing a microgrid for longer islanding durations adds to the cost, but only logarithmically. In summary, of the 256 modelled scenarios, 17 cases resulted in a net savings to the MG customer. In all other cases, the customer would pay a premium for installing the MG system. Solar PV and storage combinations contribute to the financial viability of small MGs designed for short islanding durations (e.g., 1-3 hours). Importantly, the value to the customer remains to be quantified for the additional reliability and resilience that a MG provides when operating separately from the grid.

[20] analysed the cost and operations of MGs under different business models and found that the most profitable model was where the project owner invests slowly in the MG distribution component, and where the power supply operator was responsible for the operation and maintenance of the MG network.

Second, there is evidence in the literature that microgrids play an important role in terms of curbing the power of utilities that have historically dominated national energy markets. [16] highlight the potential for the emergence of energy markets that can trade with one another, generating cost savings on electricity bills and circumventing the grid and diluting the influence of the large utilities. For example, in their evaluation of a real-time energy management system for MGs, [21] suggest that local markets of MGs can reduce the cost of power to end users by as much as $8.5 \%$. This disaggregation of energy markets and reduction in the power of dominant providers can be increased if the MGs in question are owned and managed by private companies.

Third, energy supply and security aspects of MGs are often overlooked. In an Australian context this component is critical given geographic dispersion and remoteness, and climate-related disruption. Indeed, the Australian experience has some similarities with that of the USA, where [4] suggest that the evolution of MGs was largely associated with energy resilience and security issues. That is, US-based MGs were originally constructed for single generation purposes but have since developed to incorporate distributed energy resources and larger numbers of end-users.

Energy self-sufficiency and security is similarly an important driver of the development of MGs in the EU. For example, state ownership of electricity generation remains pervasive in the Czech Republic [22]; existing energy generators remain dominant in France, Italy, the Netherlands, the UK (at the time an EU member), and Switzerland [23-27]. In contrast, smaller market participants have emerged in Denmark and Germany [28,29] as more liberal policies have emerged. In Germany in particular, to accelerate the adoption of renewable energy, government-regulated feed-in prices and access have provided financial security and assisted with long-term planning of MGs, supported by a longstanding political consensus across the major parties. Existing energy utilities have also embraced renewables and have worked with community groups to develop new 
projects. In effect, these utilities have adopted a role as both market participant and wider industry lobbyist for renewables [30,31].

Fourth, MGs in local energy markets increase energy efficiency because electricity is almost always generated in close proximity to the end users, thus limiting lossed from transmission [16]. By way of comparison, in a centralised energy system, losses due to transmission and distribution typically amount to $10-12 \%$ of total power generated [32]. Fifth, a major area of current focus is the development of pricing models for peer-to-peer (P2P) trading of electricity within MGs. Also, as noted above in Germany, governmentregulated, feed-in pricing has encouraged the establishment of renewable energy applications, including MGs. Using three different ownership structures, [33] tested an agent-based model of P2P trading on a shared PV system serving a small district comprising 48 apartments in a local community. They noted that (1) social and cultural differences among households have a substantial impact on self-sufficiency; (2) high cumulative energy demand is more effective than high self-sufficiency in exploiting the shared renewable resource; and (3) different selling prices generate various business opportunities. [34] extol the benefits of matching generation with demand through a P2P trading model, findings supported by [35] and [36], the latter utilising a hierarchical P2P trading network. In a similar vein, [37] used three different business models and representative market paradigms - bill sharing, mid-market rate and an auction-based pricing strategy - to validate the effectiveness of the proposed P2P trading mechanisms and identified the benefits.

\subsubsection{Potential sources of finance}

As shown in Figure 2, another significant component of the development of MGs is financing. Depending on the design, the construction of microgrids may involve a large amount of capital investment. Although cost data for MGs is scant, a global case study commissioned by the California Energy Commission of 26 MG projects estimated the average cost is approximately USD3 million per MW [38]. Based on this finding, the average cost of a MG project is approximately USD20.1 million, but can range from USD0.62 million for a small university-based microgrid in Shanghai to USD337.5 million for an island of 40,000 inhabitants in Denmark. ${ }^{1}$ Thus, the financing decision of MG assets should be given careful consideration.

The business model for MGs in Australia may include an ownership structure that comprises multiple customers, multi-stakeholders, utility companies and third parties [12]. Multi-stake ownership structure facilitates project funding by allowing access to capital from multiple stakeholders while reducing the capital contribution from an individual stakeholder. This will also provide access to a large amount of capital needed for largescale MG projects that integrate a wide array of hybrid generation systems employing two or more energy renewable power sources, including biomass, hydroelectric power, photovoltaic and wind turbines. Regardless of the ownership structure and project size, a

1 See page 4 of the CEC report. The average generating capacity is 6.7MW, excluding the Bornholm Island project. USD0.62 million ( $=0.206^{*}$ USD3 based on $\left.206 \mathrm{~kW}\right)$ and USD337.5 million $\left(=112.5^{*} \mathrm{USD} 3\right.$ based on $\left.112.5 \mathrm{MW}\right)$ 
critical aspect of the MG business model should encompass a well-articulated project aim that is designed to enable a steady revenue stream over the project lifespan, which in turn, increases the likelihood of raising the required capital from stakeholders. Conversely, a project characterised by a highly uncertain stream of future cash flows increases the perceived project risk, leading to higher overall financing cost while leaving the project unattractive for any potential financier.

Nevertheless, uncertain revenue streams can be managed through a business model that establishes a strong link with a core customer base. With predictable loads from these customers, long-term revenue streams for a MG project can be secured. The establishment of such an "anchor" group of customers is particularly vital for projects that are based in rural communities which are typified by a limited revenue source [39]. [40] note the importance of community commitment translating into financial commitment to achieve the necessary return on investment. Community ownership can be based on a co-operative or trustee model, with preferential pricing to members. Utilities may act as expert management companies, and would bring the added benefit of project development, access to finance and vendor assistance [40].

[30] identified three broad ownership models (outlined below) based on their survey of 67 renewable energy organisations across 18 countries covering Europe, North America, South America and Asia. The benefit of these structures is they allow single source financing, smaller consumers can acquire capital ownership, shares are tradeable, there can be a pooling of voting rights on a trustee board that may be independent or can be representative of owners, although there may be a need to limit voting rights (e.g., 33\% or $40 \%$ ) in larger groups to avoid individuals gaining a controlling stake. Ownership can also be limited to those who are members of the micro-grid and/or those in close proximity. As noted in Section 3.2.1, these three ownership models are alternative natural developments of existing consumer-based models in Australia. The three types of ownership model are:

(1) Operating company with shareholders (investors, local investors and trustees on behalf of consumers), where the operating company sources the loan and operates the MG. The trusteeship provides consumer representation, while allowing larger owners some comfort as well. Consumers can re-invest earnings into greater shareholding of the operating company. Tradability of consumer shares through trusteeship minimises disruption to other co-owners, and there is a cap on voting rights.

(2) A holding company is the owner and manager of the MG business. Financing and ownership are through the holding company. This structure also forms the basis of the third model.

(3) The third alternative is where the holding company controls more than one operating MG company, allowing for expansion geographically or horizontally.

Table 1 shows the potential sources of finance in Australia for various types of MGs. Sources of funding vary according to the MG types and ownership structure. Funding through government grants has become more widely available as more MG owners are presented with opportunities to take part in grants and subsidies supported by Federal or 
State clean energy programs. Subsidies in the form of direct funding may be available from the government to support the various stages of the project development.

Funding from the Federal Government such as the Regional Australia MG Pilots Program (RAMPP) through the Australian Renewable Energy Agency (ARENA) ${ }^{2}$ is aimed at providing funding for $50 \mathrm{MG}$ projects in regional areas. Financing through more traditional commercial loans is usually supported by the lender's commitments to climate-related innovations. In this instance, a favourable lending rate may be available to a MG owner when the project integrates renewable generation in energy delivery. The use of a mix of debt and equity as a financing strategy allows the MG owner to maintain some degree of flexibility in managing their overall project cash flows. Typically, debt instruments stipulate regular repayments of capital while the equity holders are only rewarded when the project is proven to be profitable. Venture capitalists may also play an important role in funding for MG projects that focus on the development of innovative solutions. In the case of a renewable energy venture capital fund, the Australian

Table 1. Sources of capital for microgrids

\begin{tabular}{|c|c|c|c|c|c|}
\hline \multirow[b]{2}{*}{ Capital/revenue source } & \multicolumn{5}{|c|}{ Microgrids by ownership types/users } \\
\hline & Customer-owned/mixed & $\begin{array}{l}\text { Public } \\
\text { utility }\end{array}$ & $\begin{array}{l}\text { Third } \\
\text { party }\end{array}$ & Community & Industrial \\
\hline Grants from government. & & * & & * & \\
\hline Commercial loans & * & * & * & * & * \\
\hline Debt/equity (private investors) & * & & * & * & * \\
\hline Debt/equity (public investors) & * & * & & * & * \\
\hline Venture capital/private equity & * & & & & \\
\hline Community cooperatives & * & & & * & \\
\hline Energy agreement (ESA/PPA) & * & * & * & $*$ & * \\
\hline
\end{tabular}

Government (through agencies such as ARENA) 3 can enter into partnerships with private investors to provide large-scale funding for MGs that adopts renewable energy systems ${ }^{4}$. Future revenue streams can be further guaranteed through power purchase agreements (PPA) made between the customers and the MG owner. Energy Service Agreements (ESA) can also be drawn up between the parties to provide sustainable revenue streams. For an interconnected MG, any excess power generated can be sold back to the grid, creating the necessary revenue to enhance financing feasibility.

\footnotetext{
2 https://arena.gov.au/funding/regional-australia-microgrid-pilots-ramp/

${ }^{3}$ For example, AUD100 million was allocated in 2011 by the Australian Government to establish the Renewable Energy Venture Capital (REVC) Fund dedicated to the development of renewable energy solutions in Australia.

${ }^{4}$ Through the Renewable Energy Venture Capital Fund, ARENA funded up to AUD100 million in 2015 and AUD75 million in 2018.
} 


\subsection{Community Microgrids}

The expansion in distributed energy has enabled communities to take control and, in some cases, achieve ownership of their energy destiny and invest in standalone systems quite separate from the grid. As a result, community MGs are being embraced particularly in regional and rural areas of Australia to reduce the cost and inconvenience of centrally generated power. In an Australian spatial context, the management aspects of such community MGs demand special attention.

[40] note that the existing body of literature on community MGs is concentrated on the technical and economic dimensions; academic publications on institutional design and business models are rare. In possibly the first attempt to interpret the institutions of community MGs from a social science perspective, [28] described a 'common pool resource' approach to address the institutional character of governance, social acceptance and innovation related to sustainable management of social-technical systems such as MGs. He argued that to effectively establish such systems requires institutions that unite currently separate and poorly coordinated decision making, support mutual trust, and generate suitable governance frameworks and policies to cultivate favorable conditions for new technologies. Community acceptance of these systems is crucial, while acceptance by all actors either public or private is largely determined by the institutional arrangements of ownership and control.

Relatedly, noting the absence of robust and mature business models, [41] define three key constituents of a business model for rural off-grid MGs comprising customers' willingness to pay, creation of indirect social and environmental value, and bottom-up community-inclusive design. [42] identify that some locations are well suited to solar and wind power that allow self-sufficiency from the wider electricity grid. Furthermore, they suggest that this self-sufficiency allows the MG model of distribution to be more profitable as it avoids a reliance on the wider grid for peak electricity, thus avoiding demand charges from the wider grid.

Focusing more closely on the value proposition, [43] present a sophisticated two-stage optimisation framework for design and operation of both urban and remote community MGs in a deregulated environment. In the first stage, a third-party based investment platform is developed to attract multiple stakeholders to invest in community energy systems comprising multiple distributed energy resources. A novel P2P-based business model has been developed in stage 2 that facilitates the active participation of consumers, producers and prosumers by means of transparent distribution use of the networked systems. The objectives of the proposed market model and energy management system are to minimise the daily operating cost of community systems, while maximising the benefits for all stakeholders. The proposed model is supported by multiple case studies from both urban and remote community MGs.

Results from these case studies reveal that both urban and remote communities have potential to generate techno-economic benefits but require third-party investment under long-term contracts. The designed community MGs can also operate in islanding mode, for long duration, under a regulated internal retail market. Community market models 
allow for grid upgrades specific to a location rather than across the whole network, thereby improving operational efficiency and reducing operational complexity. In one example of an internal market for a community MG, [44] investigate optimal operation, proposing an iterative bi-level model to simulate the interaction between the community MG operator and multiple parties, in order to obtain approximate market clearing results during the MG's normal operation status.

Storage adds another dimension to community MGs. Investigating eight demonstration projects in Germany and Western Australia with capacities between 100 and $1100 \mathrm{kWh}$, [45] found that models relying on the transmission of electricity from individual rooftop photovoltaics to a shared storage system through the public grid are facing significant regulatory barriers. Removing these policy barriers would enable a more efficient use of electricity storage. By contrast, projects relying on a less regulated MG managed by the administration or strata entities of multi-household developments already seem promising under the current regulatory framework.

In terms of governance, [40] examine the optimum conditions for public, private or hybrid financial ownership, and for unified or network governance through long-term contracting. This allows ex-ante investment uncertainty and ex-post appropriation risks to be efficiently managed. The analysis suggests that long-term contract completeness, future demand for electricity and levels of uncertainty are the determining factors in the selection of institutional structure. This has significant real-world implications for the communities seeking to achieve electricity self-sufficiency and environmental benefits through community MGs, service providers and other private or public actors. [29] reminds us of the importance of the social aspect of acceptance and governance to the successful implementation of MGs.

Having local ownership or other involvement assists regional value creation, the identification of suitable locations and wider community acceptance [31]. [46] suggest that community involvement also assists both the political and social-institutional dynamics in the business model and ownership structure. It also allows firms to gain the required legitimacy to access resources and finance. Moreover, community-based MGs are often closely associated with self-sufficiency, local determination, engagement and empowerment. They can also lead to economic re-generation and social cohesion benefits. Community ownership can be achieved through financial investment or managerial control by or on behalf of members of the public. Partial ownership may exist where, for example, the community may own some of the wind turbines in a wind farm or a percentage of the solar panels in a solar farm [47]. In a Danish context, [48] quote Arnstein's ladder of the different levels of citizen participation from no participation, to tokenism, and to citizen power, where in a renewable energy MG context citizen power equates to citizen ownership (or community energy). "Community" can also take different meanings, ranging from community of location to community of interest. Community ownership is different from local ownership and consumer ownership. In Denmark, different models include prosumer, individual ownership (of say one turbine) either locally or distant, co- 
operative (local and national), guild (local and distant), municipal government or company, or even foundations.

Community support for a MG can be for economic, environmental and/or social reasons, e.g., cheaper electricity, energy security, creating a greener cleaner community, or creating local employment. Thus, there are environmental, social, and economic benefits for community or citizen-based MG projects in addition to purely financial benefits [30]. This emphasises the need to consider both socio-economic and socio-technical aspects of the MG to bring together the goals and interests of all stakeholders. Finding the balance between community participation and equity while encouraging long-term investment is critical. Major deficiencies exist in creating incentives, and commercial models for maximising the economic benefits to the customer, the existing utility, and the wider community. Good governance and management are also important, as are incentives and compensation to community and consumers [40].

[49] suggest that there are two additional dimensions when considering community energy and more specifically MGs. The first is the process dimension, i.e., who is the project being developed by and how will it operate and who has influence? The second is an outcome dimension, i.e., how are the outcomes from the MG spatially and socially distributed, or who benefits economically and socially?

The formative nature of MGs in Australia continues to shape the context of community projects and the nature of the actors involved. Indeed this has been acknowledged by the Federal government funding 37 pilot projects [7]. [49] note that power utilities continue to play a critical role, while formal and informal actors exert significant pressure on them to alter their business models and shape government regulation to allow for community MGs. Significant institutional barriers remain globally, while in Australia limited government ambition has meant that community projects have been driven largely by end users or consumers, grappling with the problem of discovering an appropriate business model and a need to seek-out third-party investors, resulting in limited community benefit.

\section{Discussion}

The resurgence in interest in MGs experienced during the last three years in Australia has been prompted by concerns about energy security and resilience in the face of recent bushfires and climatic disruptions. It has also been supported by Federal government funding for 37 pilot projects across Australia. Moreover, the rapid emergence of affordable options for standalone renewable energy generation and storage has accentuated this interest, with MGs providing an option for distribution and delivery of clean electricity to end users without the challenges of the national grid. The pilot project activity has coalesced around three primary axes - vulnerable regional communities; remote indigenous communities; and rural and regional farms and farming groups. In addition, there are notable MG developments in urban areas such as at the Monash University site. Different business models have emerged out of the varying nature of these projects, shaped by ownership structures, local contexts and related challenges and opportunities. While the 'commercial imperative' remains ever present for stakeholders, it is in many instances supplemented by social and/or environmental concerns specific to the particular 
MG community. This has served to complicate the development of appropriate business models. Although the value proposition of MGs is relatively well understood, the ability of these projects to capture various aspects of value is proving elusive. A significant issue is the need to involve end users at an early stage, when many are unsure of their commitment, in decisions related to the developing usage patterns and pricing. Such decisions must be palatable and workable, and made in a collaborative framework with typically a small number of actively-engaged end users. Building customer commitment through piloting and other engagement remains critical to pricing, business models and ultimately to the success of these ventures.

The relative novelty of renewable MGs means that there is only limited past data to drawon to assist with their development. Meanwhile knowledge sharing across projects in Australia seems to be happening only in an informal manner. As a result of this early stage and rather fragmented innovation, the evolution of MGs remains in a state of flux. Perhaps this explains the modest number of commercially-viable operational MGs in existence. Moreover, the slow pace of growth has meant that the institutional infrastructure required to support their development, such as investors and regulators is yet to materialise. Novelty has also meant that project leaders are finding it difficult to obtain finance.

Similarly, the broader literature on MGs can be seen as emergent at best. To date, there has been a strong focus on the more technical aspects of MGs, but only minimal consideration of the management and commercial aspects of the technology. This paper has attempted to redress this balance and explore issues related to business models, ownership structures, financing and end user pricing. The aim has been to advance the management discourse about MGs. However more work needs to be done in this emergent space if a more comprehensive understanding of MGs is to be achieved. Future areas of research include key questions about all aspects of the sustainable business model - value proposition, value delivery and value capture - with particular emphasis on delivery and capture. Similarly, more investigation is needed of commercially viable business models more broadly and the accompanying ownership models. Finally, in the context of vulnerable and remote communities, a supportive institutional framework needs to be explored, defined and developed if the 37 government-supported pilot MG projects are to be scaledup. Only if they break out of their innovative niche and are mainstreamed can they be regarded as successful.

Author Contributions: Conceptualization, S.W., M.F., A.W. and K.A.P.; methodology, S.W., A.W. and K.A.P.; validation, S.W., M.F. and A.W..; formal analysis S.W., M.F., A.W. and K.A.P.; investigation, , S.W., M.F. and A.W.; writing-original draft preparation, S.W., M.F. A.W. and K.A.P.; writing-review and editing, S.W., M.F. A.W. and K.A.P.; visualization, S.W., M.F. A.W. and K.A.P.; supervision, M.F. and K.A.P.; project administration, M.F. and K.A.P.. All authors have read and agreed to the published version of the manuscript.

Funding: This research received no external funding.

Acknowledgments: We offer thanks to Ms Catherine Read for her initial search of the literature.

Conflicts of Interest: The authors declare no conflict of interest. 


\section{References}

1. Warren, M. Blackout: How is energy-rich Australia running out of electricity? Affirm Press: South Melbourne, Australia, 2019.

2. Boyce, P.; Cantley-Smith, R.; Dkhissi, Y.; Ferraro, S.; Fullelove, T.; Fumei, S.; Gawler, R.; Leslie, G.; Young, D. Victorian market assessment for microgrid electricity market operators, White Paper. Monash University, Melbourne, Australia, 2019. https://www.monash.edu/ data/assets/pdf file/0010/1857313/Monash-Net-Zero Microgrid-Operator-Whitepaper 20190617-1.pdf (Accessed on 10 December, 2021)

3. Hartmann, I. The macro impacts of Australian microgrids. Energy Magazine. 2020. https://www.energymagazine.com.au/the-macro-impacts-of-australian-microgrids/ (Accessed on 10 December, 2021)

4. Lenhart S.; Araujo, K. Microgrid decision-making by public power utilities in the United States: A critical assessment of adoption and technological profiles. Renew \& Sust Ener Rev 2021, 139.

https://do.org/10.1016/j.rser.2020.110692 (Accessed on 10 December, 2021)

5. Handberg, K. Microgrids: The pathway to Australia's smarter, cleaner energy future. International Specialised Skills Institute, Melbourne, Australia, 2016. https://www.issinstitute.org.au/wp-content/uploads/2016/10/handberg-Final-LowRes.pdf (Accessed on 10 December, 2021)

6. Austrade. Microgrids, smart grids and energy storage solutions. Australian Trade and Investment Commission, Australian Government, Canberra, Australia, 2017. https://www.austrade.gov.au/ArticleDocuments/2814/Microgrids\%20Smart\%20Grids\%20and\%20Energy\%20Storage\%20Solutions.pdf.aspx (Accessed on 10 December, 2021)

7. ARENA. Arena opens $\$ 50$ million fund for regional microgrid projects. Australian Renewable Energy Agency, Australian Government, Canberra, Australia, https://arena.gov.au/blog/arena-opens-50-million-fund-for-regional-microgrid-projects/ (Accessed on 10 December, 2021)

8. Western Australia Parliament. Implications of a distributed energy future: Interim report, Economics and Industry Standing Committee, Legislative Assembly, Parliament of Western Australia, Perth, Australia, 2019. https://www.parliament.wa.gov.au/Parliament/commit.nsf/(Report+Lookup+by+Com+ID)/B78DC78FC2007FAE482583D7002E3073/\$file/Microgrids\%20Report-\%20Part\%201\%20FINAL\%20for\%20web.pdf (Accessed on 10 December, 2021)

9. Ustun, T.S.; Ozansoy, C.; Zayegh, A. Recent developments in microgrids and example cases around the worldA review. Renew \& Sust Ener Rev, 2011, 15 (8), 4030-4041. https://doi.org/10.1016/j.rser.2011.07.033 (Accessed on 10 December, 2021)

10. Genc, T.S.; Reynolds, S.S. Who should own a renewable technology? Ownership theory and an application. Int J Ind Org 2019, 63, 213-238.

11. Sachs, T.; Grundler, A.; Rusic, M.; Fridgen, G. Farming microgrid design from a business and information systems engineering perspective Bus Inform Sys Eng 201961 (6), 729-744. https://doi.org/10.1007/s12599-018-00573-0 (Accessed on 10 December, 2021)

12. Vanadzina, E.; Mendes, G.; Honkapuro, S.; Pinomaa, A.; Melkas, H. Business models for community microgrids, $16^{\text {th }}$ International Conference on the European Energy Market (EEM), 2019; pp. 1-7.

13. Martin-Martínez, F.; Sánchez-Miralles, A.; Rivier, M. A literature review of Microgrids: A functional layerbased classification. Renew \& Sust Ener Rev 2016, 62, 1133-1153.

14. Sauter, R.; Watson, J. Strategies for the deployment of micro-generation: Implications for social acceptance. Ener Pol 2007, 35(5), 2770-2779. 
15. Ubilla, K.; Jiménez-Estévez, G.A.; Hernádez, R.; Reyes-Chamorro, L.; Irigoyen, C.H.; Severino, B.; Palmaehnke, R. Smart microgrids as a solution for rural electrification: Ensuring long-term sustainability through cadastre and business models. IEEE Trans Sust Ener 2014 5(4), 1310-1318.

16. Stadler, M.; Cardoso, G.; Mashayekh, S.; Forget, T.; DeForest, N.; Agarwal, A.; Schönbein, A. Value streams in microgrids: A literature review. App Ener 2016, 162, 980-989.

17. Fridgen, G.; Kahlen, M.; Ketter, W.; Rieger, A.; Thimmel, M.. One rate does not fit all: An empirical analysis of electricity tariffs for residential microgrids. App Ener 2018 210, 800-814

18. Giraldez Miner, J.I.; Flores-Espino, F.; MacAlpine, S.; Asmus, P. Phase I microgrid cost study: Data collection and analysis of microgrid costs in the United States (No. NREL/TP-5D00-67821). National Renewable Energy Lab.(NREL), Golden, CO (United States), 2018.

19. Weng, S. Distributed cooperative control for frequency and voltage stability in isolated microgrid under eventtriggered mechanism. In 2018 Australian \& New Zealand Control Conference (ANZCC) (pp. 366-370). IEEE.

20. Li, Y.; Nejabatkhah, F. Overview of control, integration and energy management of microgrids. J Modern Power Sys E Clean Ener 2014, 2(3), 212-222.

21. Marzband, M.; Sumper, A.; Domínguez-García, J. L.; Gumara-Ferret, R. Experimental validation of a real time energy management system for microgrids in islanded mode using a local day-ahead electricity market and MINLP. Ener Cons \& Mangt 2013, 76, 314-322.

22. Maley, V.; Safarik, M.; Matousek; R. Consumer (Co-)Ownership in the Czech Republic. In Energy Transition: Financing Consumer Co-ownership in Renewables; Lowitzsch, J., Ed; Palgrave Macmillan: Frankfurt, Germany, 2018, pp. 201-222.

23. Wokuri, P.; Yalcin-Riollet, M.; Gauthier, C. Consumer (Co-)Ownership in France. In Energy Transition: Financing Consumer Co-ownership in Renewables ; Lowitzsch, J., Ed; Palgrave Macmillan: Frankfurt, Germany, 2018, pp. 245270.

24. Borroni, A.; van Tulder, F. Consumer (Co-)Ownership in Italy. In Energy Transition: Financing Consumer Coownership in Renewables ; Lowitzsch, J., Ed; Palgrave Macmillan: Frankfurt, Germany, 2018, pp. $295-318$.

25. Akerboom, S.; van Tulder, F. Consumer (Co-)Ownership in the Netherlands. In Energy Transition: Financing Consumer Co-ownership in Renewables ; Lowitzsch, J., Ed; Palgrave Macmillan: Frankfurt, Germany, 2018, pp. 319344.

26. Willis, R.; Simcock, N. Consumer (Co-)Ownership in England and Wales (UK). In Energy Transition: Financing Consumer Co-ownership in Renewables ; Lowitzsch, J., Ed; Palgrave Macmillan: Frankfurt, Germany, 2018, pp. 369394.

27. Broughel, A.E.; Stauch, A.; Schmid, B.; Vuichard, P. Consumer (Co-)Ownership in Switzerland. In Energy Transition: Financing Consumer Co-ownership in Renewables ; Lowitzsch, J., Ed; Palgrave Macmillan: Frankfurt, Germany, 2018, pp. 451-476.

28. Ronne, A.; Neilson, F.G. Consumer (Co-)Ownership in Denmark. In Energy Transition: Financing Consumer Coownership in Renewables ; Lowitzsch, J., Ed; Palgrave Macmillan: Frankfurt, Germany, 2018, pp. 223-244.

29. Yildiz, O.; Gotchen, B.; Holsetnkamp, L.; Muller, J.R.; Welle, L. Consumer (Co-)Ownership in Germany. In Energy Transition: Financing Consumer Co-ownership in Renewables; Lowitzsch, J., Ed; Palgrave Macmillan: Frankfurt, Germany, 2018, pp. 271-294.

30. Lowitzsch, J. Consumer stock ownership plans (CSOPs) - The prototype business model for renewable energy communities Energies 2020, 13(1), 118 https://doi.org/10.3390/en13010118 (Accessed on 10 December, 2021). 
31. Schreuer, A. Energy co-operatives and local ownership in the field of renewable energy - Country cases Austria and Germany. Research Report 2012/02, Research Institute for Co-operation and Co-operatives, WU Vienna University of Economics and Business, Vienna, Austria, 2012.

32. Wirfs-Brock, J. 2015. Lost In transmission: How much electricity disappears between a power plant and your plug? Inside Ener. http://insideenergy. org/2015/11/06/lost-intransmission-how-much-electricity-disappearsbetween-a-power-plant-and-your-plug (Accessed on 10 December, 2021)

33. Lovati, M.; Zhang, X.; Huang, P.; Olsmats, C.; Maturi, L. Optimal simulation of three peer to peer (P2P) business models for individual PV prosumers in a local electricity market using agent-based modelling. Buildings 2020, 10(8), 138. https://doi.org/10.3390/buildings10080138 (Accessed on 10 December, 2021)

34. Zhang, C.; Wu, J.; Cheng, M.; Zhou, Y.; Long, C. A bidding system for peer-to-peer energy trading in a gridconnected microgrid. Energy Procedia 2016, 103, 147-152. https://doi.org/10.1016/j.egypro.2016.11.264 (Accessed on 10 December, 2021)

35. Baez-Gonzalez, P.; Rodriguez-Diaz, E.; Carlini, M.A.R.; Bordons, C. A power P2P market framework to boost renewable energy exchanges in local microgrids. In 2019 International Conference on Smart Energy Systems and Technologies (SEST), 2019, (pp. 1-6). IEEE. doi: 10.1109/SEST.2019.8848998 (Accessed on 10 December, 2021)

36. Paudel, A.; Beng, G.H. A hierarchical peer-to-peer energy trading in community microgrid distribution systems. In 2018 IEEE Power \& Energy Society General Meeting (PESGM) (pp. 1-5). IEEE. doi: 10.1109/PESGM.2018.8586168 (Accessed on 10 December, 2021)

37. Long, C.; Wu, J.; Zhou, Y.; Jenkins, N. Peer-to-peer energy sharing through a two-stage aggregated battery control in a community Microgrid. App Ener 2018 226, 261-276.

38. California Energy Commission, Microgrid Analysis and Case Studies Report California, North America, and Global Case Studies, 2018, CEC-500-2018-022.

39. Robert, F.C., Sisodia, G. S., Gopalan, S. 2018. The critical role of anchor customers in rural microgrids: Impact of load factor on energy costs. In 2017 International Conference on Computation of Power, Energy Information and Communication (ICCPEIC), Melmaruvathur, India, 2018. pp. 398-403. doi: 10.1109/ICCPEIC.2017.8290401. (Accessed on 10 December, 2021)

40. Gui, E.M.; Diesendorf, M.; MacGill, I. Distributed energy infrastructure paradigm: Community microgrids in a new institutional economics context. Renew $\mathcal{E}$ Sust Ener Rev 2017, 72, 1355-1365 https://doi.org/10/1016/j.rser.2016.10.047 (Accessed on 10 December, 2021)

41. Dibaba, H.; Vanadzina, E.; Mendes, G.; Pinomaa, A.; Honkapuro, S. Business model design for rural off-the-grid electrification and digitalization concept. In 2020 17th International Conference on the European Energy Market (EEM) (pp. 1-5). IEEE. doi: 10.1109/EEM49802.2020.9221944 (Accessed on 10 December, 2021)

42. Arcos-Aviles, D.; Guinjoan, F.; Pascual, J.; Marroyo, L.; Sanchis, P.; Gordillo, R., Ayala, P.; Marietta, M.P. A review of fuzzy-based residential grid-connected microgrid energy management strategies for grid power profile smoothing. In Energy Sustainability in Built and Urban Environments; Motoasca, E.; Agarwal A.; Breesch H. Eds.; Springer, Singapore, 2019; pp.165-199. https://doi.org/10.1007/978-981-13-3284-5_8

43. Meena, N.K.; Yang, J.; Zacharis, E. Optimisation framework for the design and operation of open-market urban and remote community microgrids. App Ener 2019, 252, 113399. https://doi.org/10.1016/j.apenergy.2019.113399 (Accessed on 10 December, 2021)

44. Li, J.; Liu, Y.; Wu, L. Optimal operation for community-based multi-party microgrid in grid-connected and Islanded modes. IEEE Transactions on Smart Grid 2018, 9 (2), 756-765. doi: 10.1109/TSG.2016.2564645 
45. Müller, S.C.; Welpe, I.M. Sharing electricity storage at the community level: An empirical analysis of potential business models and barriers. Ener Pol 2018, 118, 492-503.

46. Provance, M.; Donnelly, R.G.; Carayannis, E.G. Institutional influences on business model choice by new ventures in the microgenerated energy industry Ener Pol 2011, 39, 5630-5637.

47. Walker, G. What are the barriers and incentives for community-owned means of energy production and use? Ener Pol 2008, 26, 4401-4405.

48. Gorroño-Albizu, L.; Sperling, K.; Djørup, S. The past, present and uncertain future of community energy in Denmark: Critically reviewing and conceptualising citizen ownership. Ener Res E Soc Sci 2019, 57, 101231. https://doi.org/10.1016/j.erss.2019.101231

49. Warneryd, M.; Hakansson, M.; Karltop, K. Unpacking the complexity of community microgrids: A review of institutions' roles for development of microgrids. Renew E Sust Ener Rev 2020, 121, 109690.

https://doi.org/10/1016/j.rser.2019.109690 (Accessed on 10 December, 2021) 